\title{
Pathways to a European PhD for Thermal Energy Storage
}

\author{
G. Weber \\ AIT Austrian Institute of Technology GmbH/Energy Department, Vienna, Austria \\ Email: gundula.weber@ait.ac.at \\ L. F. Cabeza and G. Zsembinszki \\ GREA Innovació Concurrent, Universitat de Lleida, Lleida, Spain \\ Email: lcabeza@diei.udl.cat \\ J. N. W. Chiu \\ KIC-Innoenergy, Stockholm, Sweden \\ Email: justin.chiu@kic-innoenergy.com
}

\begin{abstract}
Innovative Pathways to Thermal Energy Storage (INPATH- TES) is to create a network of academia, research institutes and small and medium enterprises that are cooperating in defining an innovative programme and in its deployment to implement a unique joint PhD programme on Thermal Energy Storage (TES) technologies. For the development of the $\mathrm{PhD}$ program the presence of a wide range of stakeholders ensures the inclusion of knowledge, experiences and needs. The $\mathrm{PhD}$ uses the possibility of competence \& skills driven learning outcomes to educate future students. Through the carefully designed Intended Learning Outcomes (ILOs) and Achieved Learning Outcomes (ALOs), following the EIT pedagogical methodology, learners will receive knowledge up to the necessary specific level. The future role of teachers will change and will include the design of overarching ILOs, the assembling of knowledge material and ALOs and moderate peer discussions. Main challenges were identified through the approval of the joint $\mathrm{PhD}$ programme by each of the participating countries due to the structure, doctoral training and the access to a PhD programme. Nevertheless the final result of such a network will lead to a qualification of professionals in these technologies for European Research and Industrial Institutions.
\end{abstract}

Index Terms - thermal energy storage, thermal energy storage technologies, PHD programme, international master programme, INPATH-TES, intended learning outcomes, achieved learning outcomes

\section{INTRODUCTION}

The European Strategic Energy Technology Plan (SET-Plan) was established as a strategic plan for energy technology policy in Europe which comprises measures related to planning, implementation, resources and international cooperation in the field of energy technologies. Moreover, the European Commission (EC) SET-Plan Education and Training Roadmap (E\&T) [1] is targeted at bringing a structural change in the European

Manuscript received July 11, 2016; revised October 17, 2016.
Union (EU) educational landscape by enhanced integration and coordination of the business and the research environment. The SET-Plan Roadmap Education has identified clear gaps in linking Higher Education Institutions together for more efficient PhD education, and especially to include practical training with research infrastructures and experimental facilities [1].

Based on this gaps and technological needs in the area of thermal energy storages (TES), the project Innovative Pathway for PhD research in Thermal Energy Storage (INPATH-TES) was developed and funded within the framework of the research and innovation programme Horizon 2020 by EC.

The goal of INPATH-TES is to create a network of European partners in at least 14 countries consisting of 13 universities, 4 research institutes, 3 industries and 2 SME that are cooperating in defining the programme and in its deployment to implement a joint $\mathrm{PhD}$ programme on TES technologies. The final result of such a network will lead to a qualification of professionals in these technologies for European research and industry institutions.

The specific objectives and outcomes of INPATH-TES are to:

- establish a unique joint PhD programme in the field of TES,

- develop minimum 20 ECTS equivalent common training modules,

- develop four technology oriented PhD courses,

- establish one annual joint workshop for $\mathrm{PhD}$ students,

- graduate $28 \mathrm{PhD}$ students per year, and

- Exchange 14 PhD students per year between industries and academia.

The partners in this joint $\mathrm{PhD}$ will be the core of a future larger network of excellent $R \& D$ institutions, and industries for co-funding and industrial placement, sharing infrastructure capacities, and enhancing mobility of students. 


\section{ApPROACH AND Methotology to Establish A JOINT PHD ON TES}

The overall approach of INPATH-TES involves a work plan divided in six work packages, being either coordination or support activities. The main coordination activities contain development, maintaining and updating of the $\mathrm{PhD}$ programme in INPATH-TES and the implementation of the $\mathrm{PhD}$ programme. Main support activities are stakeholder involvement, expansion of partnerships, monitoring, evaluation of INPATH-TES intellectual property rights, and regulatory framework.

For the development and implementation of the PhD programme, the presence of a wide range of relevant stakeholders ensures inclusion of knowledge, experiences and needs in the project for high impact visibility. Stakeholders provided input to the training agenda from a user and societal perspective and help define urgent training and R\&D needs. Their involvement in the development of the training agenda, its implementation, and INPATH-TES as a whole, is likely to bring training outcomes closer to implementation and enhance the social value of the training initiatives and the joint programming. Communication with stakeholder is also important to raise awareness of the importance of INPATH-TES across the EU.

Therefore, in a first step relevant stakeholder groups were defined within the consortium which included policy makers, industry, small and medium enterprises (SMEs), academics, students and non-governmental organizations (NGOs). A general communication strategy was agreed and implemented which contains communication on a regular basis via newsletter and information materials, the organization of events such as breakfast meetings and conferences for policy makers and scientists. At least one international workshop and 14 national workshops are planned in each of the participating country. The focus of the workshops is a transfer of knowledge concerning the current status of the technologies, technical and regulatory aspects, supporting measures, and to increase the level of awareness of INPATH-TES.

Besides these main activities, an online based questionnaire was developed and completed by the stakeholder groups mainly industry, research centers and SMEs with regard to expectations, needs and future demands of the industry involved in TES technologies. The questionnaire encompassed 14 courses corresponding to the main aspects of the joint $\mathrm{PhD}$ programme (thermal energy storage, research management, dissemination and communication and thermal energy storage specialization), the content of which was evaluated along with the curriculum relevance. Many industrial responses reported the most attractive technical topics as being research methods, thermal energy technologies, the role of thermal energy storages in an energy system, development of new thermal materials, experimental testing, design, modelling, and optimization of thermal energy storage systems. The most interesting nontechnical topics were beside energy policies in Europe and international, the basics of patents, the technical implementation of an idea to a product and the publication in a scientific journal.

Furthermore, expectations on $\mathrm{PhD}$ students in general and in the area of TES have been communicated through the survey participants. In parallel, the willingness of hosting a student in the research institute or company and to contribute to the $\mathrm{PhD}$ programme has been confirmed.

For the development, maintaining and updating of the PhD programme, first a benchmark on $\mathrm{PhD}$ level education in the field of "energy storage" was made, the findings were reconfirmed and consolidated from the SET-Plan E\&T Roadmap [1], a curriculum that can be implemented from a global perspective in ECTS awarding institutions was suggested.

The concept is to build up small and easy to manage "learning modules" that in different ways can be "packaged" towards courses that the respective $\mathrm{PhD}$ supervisors, and their respective universities, can adapt to their own needs with approval of the PhD programme board. The developed learning material is implemented in the constructive alignment perspective in the European Institute of Innovation and Technology (EIT) with the KIC InnoEnergy pedagogical methodology of studentcentered learning, aligned teaching, and active learning [2]. This methodology is implemented in an e-learning perspective and can, as such, be used in both traditional classroom settings as remotely through flipped classroom model.

The approach is that the developed different Learning Modules will be stand-alone up to a certain level. As such they will, through the carefully designed Intended Learning Outcomes (ILOs) and Achieved Learning Outcomes (ALOs), ensure that the learners will receive knowledge up to the specific level before the knowledge experts will come into the education if required.

Therefore, it is possible for learners to reach a certain knowledge-level in a completely remote setting, whereas the learners who may want to progress even further into the learning process will have access to the additional knowledge materials in the follow-up level [3].

The online learning platform self-learning section consists of recorded learning videos cut into short segments for efficient learning. In order to get hands-on practice of the crucial technologies students will get access to remote lab exercises and also interactive simulations. Other parts are filmed study visits and online literatures. This will, as with the course material, allow remote learners to learn from the infrastructure, be part of the full discussions of the physical goal of the infrastructure and reach a significant improved knowledge level. With this approach, it is possible to perform highly complex technical experiments and learn from these, remotely.

Each section is followed with tracked self-assessment where students' performance can be followed up continuously and serve for pedagogic purpose. Randomized automatically corrected calculation exercises are to be programmed so that students may test their skills and knowledge at their convenience. Online meetings with field experts will then lead to in depth 
discussions on certain aspects of the problems encountered by students. This will allow deeper interaction among students and teachers.

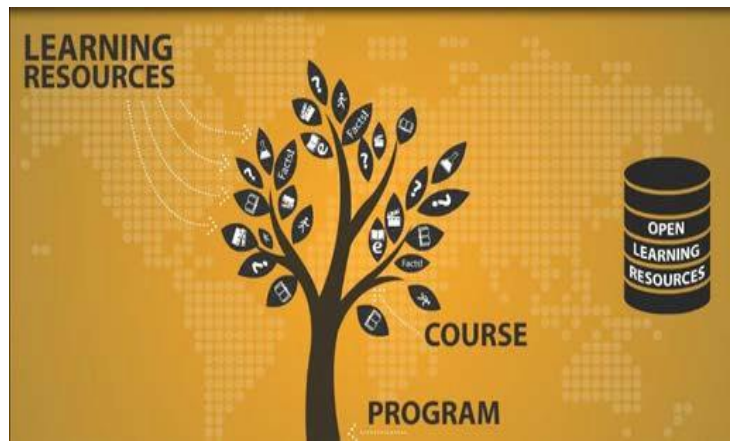

Figure 1. Example of e-learning material in the form of "Learning Modules" [4]

This pedagogical methodology shows several advantages, such as reusability of knowledge material produced (with potentially different ILOs and ALOs) for different levels of trainings; the $\mathrm{PhD}$ teaching advisory board (TAB) will have the possibility to attain high-level discussions with students instead of basic, ex-cathedra unidirectional communication, and it opens up a larger, global possibility for learners to assimilate knowledge from the INPATH-TES. As the knowledge is built up in smaller "Learning Modules" it is possible for knowledge providers to build up their own courses based upon these Learning Modules in combination with their own specific interests, see Fig. 1. Such an approach will greatly enhance the teachers' interest and motivation to also in the future share their own developed learning modules and will as such enhance a European data-base of repositories of knowledge transfer.

As explained, the educator's role will change to an architect of the training content and materials, moderator and assessor keeping the human aspect in a larger and remote "learning process" [5].

As also the typical future learner will change in the next decades there is a need for a more flexible design of education and training programs as described. The focus of the next years will be on independent learning, not on teaching. Future learners will seek of knowledge from anywhere available at any time with possible selfassessment and preparation. With the explained method all teaching materials are available at any time also at home or for students from various countries not just in the classroom. Due to more quality time instead of quantity time within the learning process it will lead to a better understanding of the topics. Competences \& skills will, in future, also be proven in other ways than programs and degrees.

One direct challenge and opportunity resulting from the joint $\mathrm{PhD}$ programme is the possibility of cosupervision [6]. A mutual understanding of the roles of all the co-supervisors and that of the $\mathrm{PhD}$ candidate would add clarity to the expectations to all parties. The relation between supervisors and students is meant to gradually shift towards advisor-executioner. This is the pinnacle of the INPATH-TES constructive aligned supervising process where the supervisors will play more as a consultant role where the student may reflect and evaluate the adequacy of the mentoring so as to act as an independent researcher. In addition, throughout the study period, individual study plans (ISP) are to be drafted by and for each of the student to monitor the progress of the students and to keep students on track according to the INPATH-TES curricula. These are some of the means that may assist $\mathrm{PhD}$ candidates in reaching their goal of obtaining their degree in time with professional quality.

Another crucial coordinating activity is the implementation of the joint $\mathbf{P h D}$ in the partner countries, as it is a key success factor for the future of the $\mathrm{PhD}$ Programme. Mainly the different legislative barriers and the composition of a $\mathrm{PhD}$ programme in the partner countries were evaluated. Main differences were found in the regulation and scope, the structure of the $\mathrm{PhD}$ programme, potential doctoral training (mandatory or not), the skills to be acquired by the student, the access to a $\mathrm{PhD}$ programme, admission criteria and the $\mathrm{PhD}$ programme requirements. Among the European participating countries in the joint $\mathrm{PhD}$ programme, namely Austria, Belgium, France, Germany, Ireland, Israel, Italy, Latvia, Netherlands, Poland, Portugal, Spain, Turkey, UK, the duration of a $\mathrm{PhD}$ varies from 2 to 5 years. PhDs are offered in all countries in the framework of a full or part time study. In most of the countries, the supervisor assumes the principal role in determining doctoral training curriculum. In all of the participating countries, a Master degree is mandatory to access a $\mathrm{PhD}$ programme (exceptions in Ireland, UK and Poland). Hence for the implementation of the joint $\mathrm{PhD}$ programme a common approach in line with the legislative framework in each country must be defined and agreed on.

\section{CONCLUSION FOR THE IMPLEMENTATION OF THE JOINT PHD}

Following the EC SET-Plan E\&T Roadmap, the concept of the project INPATH-TES is a unique joint PhD programme between universities and research centres, on the topic of TES which will consist of common courses mandatory for the foundation of the students' training. These $\mathrm{PhD}$ courses strengthen $\mathrm{PhD}$ study through providing specialist underpinning.

To ensure smooth transition of the new PhDs to the industry, common courses of 20 ECTS will be established. The Universities will share knowledge on common topics such as technical writing and science dissemination, intellectual property protection, entrepreneurship, business models, project management and research funding. With this approach an optimization of university resources by using e-learning and Massive Open Online Courses (MOOCS) technologies is foreseen.

Out of the $\mathrm{PhD}$ development, these courses will allow the development of an international Master degree programme (MSc) in TES. Wider dissemination access with direct industrial relevance and deployment aspects focusing on developed future markets is expected. 
As workshops and conferences for different stakeholder groups are foreseen, a dissemination of the knowledge inside and outside the network on one hand and on the other hand an exchange of external $\mathrm{PhD}$ students is planned.

Through active engagement with different stakeholder groups in the project, research and market oriented inputs to the $\mathrm{PhD}$ topics were set up in the training courses. Through an online survey it was shown that over $85 \%$ of the survey participants were satisfied with the proposed content and $2 / 3$ would host a student in their company. Expectations from industry and research institutes on PhD students can mainly be summarized in: 1 . personal abilities e.g. multidisciplinary, creativeness, impact awareness; 2. social, economic and technical abilities e.g. understanding of the fundamentals of relevant technological aspects of thermal energy storage, R\&D, applications and markets, modelling, system integration, testing and characterization of products. The reported most attractive technical and non-technical topics from the industry were taken into account within the process of defining the courses.

In the traditional on-campus way many teachers still "turn their back to the learners", repeat the same messages year by year and write the same old classical equations. Furthermore thousands of general online courses exist but there is a very low success rate compared to registrations. Therefor INPATH-TES uses the possibility of competence \& skills driven learning outcomes to educate future students.

The future role of teachers will be the design of overarching ILOs, the assembling of knowledge material and ALOs and moderate peer discussions, Fig. 2.

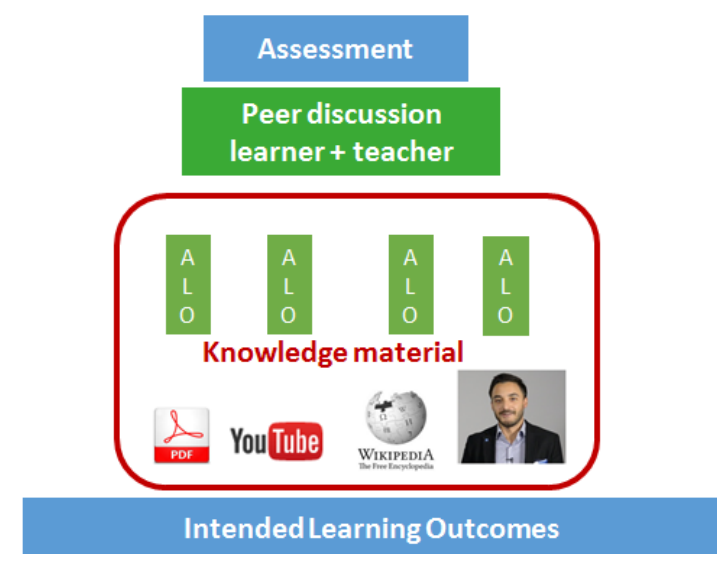

Figure 2. Pathway to future training [4]

By creating further synergies between INPATH-TES and other global organizations and initiatives, extension of the partnership and exchange of students are foreseen.

Main challenges that have been identified are the approval of the joint PhD programme by each of the participating countries. Although all participating countries in INPATH-TES are within Europe, differences in the regulatory framework for the establishment of $\mathrm{PhD}$ programme subsist. The structure, the programme requirements and the admission criteria vary. It was found out that a simpler solution to cooperate between Universities in that area is to start a Joint supervision $\mathrm{PhD}$. A similar challenge exists with Master Degree programs and therefore Memorandums of Understanding, credit point agreements and wider Bologna principles will be observed.

\section{ACKNOWLEDGMENT}

This work is supported by funding from the European Union's Horizon 2020 research and innovation programme under grant agreement No 657466.

\section{REFERENCES}

[1] JRC Coordination Strategic Energy Technology (SET) Plan Roadmap on Education and Training, 2014.

[2] J. Biggs and C. Tang, Teaching for Quality Learning at University, ISBN-13: 978-0335242757, 2011.

[3] J. N. W. Chiu, PhD Course MJ3335/MJ3336 Educational Aspects in Energy Technology, KTH- Royal Institute of Technology, 2016.

[4] T. Fransson, "The future of education in KIC InnoEnergy," presented at the World Engineering Education Forum, Dubai, Dec. 3, 2014

[5] 'Quality for learning' EIT Quality Assurance and Learning Enhancement Model, European Institute of Innovation and Technology (EIT) as a body of the European Union, 2016.

[6] E. Phillips and D. Pugh, How to get a PhD: A handbook for Students and Their Supervisors, 2010.

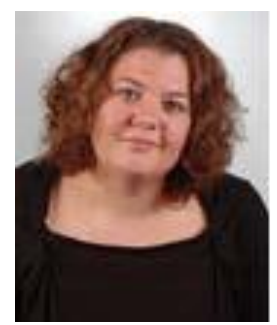

Gundula Weber holds a degree in building technologies and environmental energy and has been working as Engineer for AIT since more than 10 years.

She is coordinating AITs vocational education in the fields of photovoltaic, heat pumps, solar thermal energy and ventilation and has been involved in various national and international dissemination, quality assurance and technology transfer projects in these fields (e.g. QualiCert, Cer ${ }^{2}$, EAST-GSR, TRANSSOLAR, etc.). Since 2008 Mrs. Weber is an external lecturer in the fields of energy efficiency, solar thermal technologies and photovoltaic systems and planning at the University of Applied Sciences Technikum Vienna, the University of Applied Sciences in Wiener Neustadt and the University of Applied Sciences in Pinkafeld. Mrs. Weber was Head of the EHPA's Education Committee.

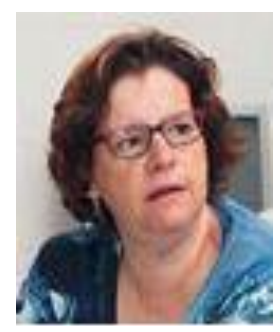

Luisa F. Cabeza holds a $\mathrm{PhD}$ on Industrial Engineering and leads the research group GREA Innovació Concurrent at the University of Lleida, created in 1999, when she joined the institution. Today she is a full professor in Thermal Engineering.

She has published more than 200 scientific papers and has participated or leaded national and international projects in the topic. Within EU funded projects, we can find MOPCON (FP6), EFFIBUILDINGS (FP7-People), HESTOR (FP7-Capacities), MERITS (FP7-Cooperation), INNOSTORAGE (FP7-People-IRSES), and INPATH-TES (H2020-CSA). Prof. Cabeza received several research awards, such as Premi Narcis Monturiol 2012 and ICREAAcademia 2013-2017. 
Justin N. W. Chiu holds a $\mathrm{PhD}$ degree in Thermal Energy Storage from KTH Royal Institute of Technology, Stockholm, Sweden. $\mathrm{He}$ carried out postdoctoral studies at Graduate Institute of Environmental Engineering, National Taiwan University, Taipei, Taiwan. Currently he leads the work package: developing, maintaining and updating $\mathrm{PhD}$ programme in Thermal Energy Storage in the EU H2020 funded project Innovative Pathways to Thermal Energy Storage. Dr. Chiu is a member of the International Energy Agency, American Society of Mechanical Engineers and is responsible for PhD level course MJ3335/ MJ3336 Educational Aspects in Energy Technology at KTH, Stockholm, Sweden. 